\title{
Geraldo de Barros e José Oiticica Filho: experimentação em fotografia (1950-1964)
}

\section{Carolina Etcheverry ${ }^{2}$}

RESUMO: $\bigcirc$ presente artigo tem por objetivo apresentar os fotógrafos brasileiros Geraldo de Barros e José Oiticica Filho e suas fotografias. Assim, contextualiza-se o período de fins da década de 1940 até 1964, ano da morte de Oiticica Filho, abordando a história da fotografia brasileira e sua relação com a história da arte, bem como a questão da abstração. Desse modo, temos a história da fotografia moderna brasileira relacionada com os movimentos concretos e neoconcretos. Ao mesmo tempo, este artigo busca também fazer uma revisão crítica dos textos escritos sobre estes fotógrafos e suas imagens, a fim de estabelecer sua importância além do campo fotográfico.

PALAVRAS-CHAVE: Fotografia. Experimentação. Vanguardas. Geraldo de Barros. José Oiticica Filho. Fotógrafos brasileiros.

ABSTRACT: The objective of this paper is to introduce the Brazilian photographers Geraldo de Barros and José Oiticica Filho and their work. Set between the late 1940s and 1964 - the year of Oticica Filho's death - the article discusses the history of Brazilian photography and how it relates to the history of art, as well as the issue of abstraction. By doing so, it shows how the history of modern Brazilian photography interacts with the concrete and neoconcrete art movements. In addition, the author offers a critical review of the texts written about these two photographers and their images as a means to determine their importance beyond the field of photography.

KEYWORDS: Photography. Experimentation. Avant-garde. Geraldo de Barros. José Oiticica Filho. Brazilian photographers.

Um bancário e um professor de entomologia são responsáveis pela criação de fotografias que, em alguns casos, podem ser definidas como experimentais ou de cunho abstrato e que contribuíram para subverter o estatuto da própria
1. Versão final do trabalho apresentado no IV Simpósio Nacional de História Cultural, realizado em Goiânia em 2008, promovido pela ANPUH e Universidade Católica de Goiás, 2008, no âmbito do minissimpósio 1: História, Fotografia e Cultura Visual: reflexões sobre o estatuto das imagens, formas de produção e usos sociais no tempo, coordenado por Solange Ferraz de Lima (Museu Paulista da Universidade de São Paulo) e Charles Monteiro (Pontifícia Universidade Católica do Rio Grande do Sul).

2. Mestre em Artes Visuais (ênfase em História, Teoria e Crítica) pela Universidade Federal do Rio Grande do Sul. E-mail: <etchev@gmail. com>. 
3. Para entender os diferentes estatutos da fotografia, ver Phillipe Dubois (2003) Para a idéia de que a máquina fotográfica carrega consigo uma programação predeterminada, ver Vilém Flusser (1998).

4. O fotograma, segundo Busselle (1977, p. 216), consiste em fotoimagens obtidas quando objetos sólidos ou translúcidos são colocados sobre papel sensível e expostos à luz, a fim de produzir uma imagem de seus contornos ou estruturas internas. Os fotogramas foram também desenvolvidos por outros fotógrafos, tais como Christian Schad, El Lissitzky e László Moholy-Nagy, obtendo resultados plásticos diferentes entre si, visto que os objetos utilizados para obter a imagem eram também diferentes. Do mesmo modo, Geraldo de Barros e José Oiticica Filho, ao utilizarem-se dos fotogramas, obtêm resultados diferentes desses fotógrafos, visto que procuravam criar imagens abstratas dentro dos ideais concretistas.

5. A solarização, segundo Busselle (1977, p. 218), consiste em uma rápida exposição de uma cópia à luz, após a exposição normal recebida no ampliador, e uma rápida revelação, que depois é completada, bem como os processos subsequentes. Esse procedimento, que pode ser realizado tanto na cópia quanto no negativo, tem como resultado uma imagem totalmente invertida

6. Ver Moholy-Nagy (2007, p. 253). O texto data de 1943.

7. Sobre fotomontagem em geral, ver Dawn Ades (2002); e, para fotomontagem no Brasil, ver Tadeu Chiarelli (2003).

8. Moholy-Nagy (2007, p. 213). As outras sete variedades da visão fotográfica são a visão exata, a visão rápida, a visão lenta, a visão intensificada, a super-visão, a visão fotografia no Brasil. O período é o que vai de fins da década de 1940 até 1964. O contexto é o de crescimento econômico, atrelado a uma urbanização acelerada, principalmente em São Paulo, e a um fomento da cultura através da criação de espaços de arte. Em contraposição ao figurativismo, o campo artístico desenvolvia-se em direção à abstração e, então, o concretismo e o neoconcretismo eram os principais movimentos. Assim, o horizonte de perspectivas de desenvolvimento para estes fotógrafos era, pode-se perceber, promissor.

E eles fizeram bom uso do momento adequado. Geraldo de Barros lo bancário) e José Oiticica Filho (o professor de entomologia) são dois fotógrafos cujas inquietações estéticas os levaram a experimentar diversas formas de representar o mundo através de suas lentes. Ambos não fizeram uso apenas da programação que a câmera thes oferecia, mas buscaram maneiras alternativas, criativas, de usá-la, muitas vezes subvertendo o estatuto de cópia do real que a máquina carrega desde seu surgimento ${ }^{3}$. E foram, no Brasil, os precursores dessa vertente experimental na fotografia que, tanto na Europa quanto nos Estados Unidos, iá contava com adeptos importantes.

Artistas como Man Ray, Moholy-Nagy, Rodchenko e Alvin Langdon Coburn buscaram maneiras diferentes, que não a fotografia figurativa tradicional, de se expressar através da fotografia. Man Ray foi adepto dos fotogramas ${ }^{4}$, que ganharam o nome de rayogramas, porque feitos por Ray. Além destes, o artista buscou também as solarizações ${ }^{5}$, que alteram a cor da imagem, invertendo-as. László Moholy-Nagy, artista húngaro e professor da Bauhaus de Dessau, ensinava seus alunos a procurar novos ângulos para suas imagens lartifício usado também por Rodchenko, com suas tomadas de baixo para cima ou de cima para baixo - as bird's views). Moholy-Nagy elencou, em texto intitulado Surrealismo e fotografia ${ }^{6}$, três possibilidades de desenvolvimento das técnicas fotográficas: fotograma, múltiplas exposições em um mesmo negativo e fotomontagem 7 . Em outro texto mais conhecido, de 1936, intitulado Fotografia, forma objetiva do nosso tempo, o artista e professor da Bauhaus define as oito variedades da visão fotográfica, colocando em primeiro lugar a visão abstrata, através do fotograma ${ }^{8}$. Já Alvin Langdon Coburn, ao fotografar prismas, por achar que era preciso explorar ainda mais as possibilidades da câmera, acabou por criar o que chamou de Vortografias ${ }^{9}$. Todos estes artistas e fotógrafos criaram fotografias improváveis, no sentido de que, apesar de a câmera fotográfica ser capaz de produzi-las, é preciso que o seu operador - o fotógrafo-artista - seja capaz de concebê-las. Esses nossos exemplos foram capazes, e, assim como eles, Geraldo de Barros e José Oiticica Filho, seguidos de vários outros, também exploraram o potencial da câmera.

Geraldo de Barros foi adepto de práticas diversas de expansão das possibilidades da câmera fotográfica. De posse de uma Rolleyflex, fazia várias tomadas em um mesmo negativo, sobrepondo imagens, o que originou as fotografias da série Fotoformas. Também realizava fotogramas e desenhava com nanquim no próprio negativo, o que resultou em fotografias como A menina e o sapato. $O$ conjunto de suas criações, do final da década de 1940 até $1951^{10}$, foi exposto sob o título Fotoformas, no Masp, em $1951^{11}$. O título lembra o grupo vanguardista Fotoform, encabeçado pelo alemão Otto Steiner, que buscava criar fotografias 
abstratas dentro dos ideais experimentais da Bauhaus. As duas exposições realizadas por esse grupo, ambas em 1950, tiveram lugar em Milão e em Colônia. É importante mencionar o grupo, tendo em vista que, além de serem fotografias realizadas na mesma época, são tendências que se revelaram latentes, precisando vir à tona mais ou menos ao mesmo tempo, em diferentes lugares do mundo. A fotografia subjetiva alemã, da qual o grupo Fotoform faz parte, foi bastante importante no campo experimental ${ }^{12}$.

Otto Steinert, no prefácio para Subjektive Fotografie I, de 1952, explica o que seria esta fotografia:

Em contradição com a fotografia documental e utilitária, a Fotografia Subjetiva enfatiza sucinta e claramente o impulso criativo do fotógrafo individual [...] A fotografia usual, pertencente à "fotografia artística" e dependente acima de tudo das atrações do próprio objeto, dá lugar a uma abordagem experimental e inovadora. Aventuras no campo visual são, em um primeiro momento, impopulares [...] mas apenas um tipo de fotografia, simpática em relação à experimentação, pode prover os meios para moldar nossas experiências visuais. Um novo estilo fotográfico é aquele que o nosso tempo demanda. A Fotografia Subjetiva significa para nós, portanto, o quadro fotográfico englobando todos os aspectos da criação individual na fotografia - do fotograma não objetivo à reportagem profunda e esteticamente satisfatória $^{13}$.

Esta citação é bastante interessante para entender-se as fotografias de Geraldo de Barros e de José Oiticica Filho. $\bigcirc$ autor fala do impulso criativo do fotógrafo, que é enfatizado pela fotografia subjetiva, que seria criativa. Esta fotografia, por ser inovadora, não é bem aceita em princípio, mas é através dela, de sua experimentação, que surge uma nova visualidade (novas experiências visuais). Também por aqui, os fotógrafos brasileiros enfrentam tais dificuldades, ao tentar instaurar uma nova visão para a fotografia, principalmente devido à ênfase dos fotoclubes tradicionais na fotografia pictorialista, que era vista como a expressão máxima do esteticamente desejado na representação fotográfica ${ }^{14}$.

Neste sentido, José Oiticica Filho ${ }^{15}$ é um ótimo exemplo por sua trajetória fotográfica diversificada. Seu começo foi com uma fotografia utilitária ${ }^{16}$, tendo como tema os insetos de seu estudo. Essa fase, denominada acadêmica por seu filho Cesar ${ }^{17}$, teria durado cerca de dez anos, do início dos anos 1940 até o início dos anos 1950, quando Oiticica Filho trava contato com Ivan Serpa, artista que ensinou pintura a seus filhos Hélio e Cesar, e também contribuiu com as discussões sobre arte abstrata e com a condução do fotógrafo à fotografia moderna.

A segunda fase descrita por Cesar é a denominada simbolista, na qual o fotógrafo encontra-se preso à figura. Paulo Herkenhoff ${ }^{18}$ caracteriza essa fase como sendo fotoclubista, e seria marcada pela participação nas associações de amadores ligados ao pictorialismo, como já dito acima, em especial no Photo Club Brasileiro ${ }^{19}$. São dessa fase fotografias como $\bigcirc$ túnel, fotomontagem de 1951, Triângulos semelhantes, de 1953, e Um que passa, também de 1953. São imagens nas quais nota-se o rigor compositivo, que tendia, já nessa época, simultânea e a deformação óptica.

9. Ver Helmut Gernsheim (1990, p. 163). Segundo este autor, as vortografias (Coburn fotografou 18 imagens deste tipo, em um mês, expondo-as em 1917) foram assim chamadas devido ao Vorticismo, movimento inglês de curta duração (1914-1920), ao qual Coburn foi introduzido pelo poeta Ezra Pound. Sobre Vorticismo e Ezra Pound, conferir Wees $(1965 ; 1966)$.

10. Heloisa Espada Rodrigues Lima (2006, p. 11), em sua dissertação de mestrado, coloca que Geraldo de Barros começou a criar as fotografias da mostra por volta de 1948.

11. Em 2006, a editora Cosac Naify reeditou o livro com as fotografias da exposição Fotoformas, bem como imagens posteriores, da década de 1990, intituladas Sobras, realizadas com as mesmas técnicas experimentais das primeiras; ver Geraldo Barros (2006).

12. Ver Casa Andrade Muricy (2008).

13. Otto Steinert apud Helmut Gernsheim (1991, p. 196); tradução da autora.

14. Ver Maria Teresa Bandeira de Mello (1998).

15. Para mais informações sobre a obra de José Oiticica Filho, sugiro a entrada dedicada a ele na Enciclopédia Itaú Cultural de Artes Visuais (<http://www.itaucultural. org.br $>$ ) e também postagem de Rubens Fernandes Júnior, no blog Icônica (<http:// w w w . i con ica.com br/?tag=jose-oiticica-filho $>$ ). Seu acervo fotográfico, juntamente com o acervo de obras de seu filho Hélio Oiticica, estava na casa de César Oiticica na noite de 16 de outubro de 2009, quando esta pegou fogo. Segundo dados obtidos no Centro de Arte Hélio Oiticica, boa parte 
do acervo fotográfico foi danificado, esperando agora por restauração. Restam as imagens digitalizadas em alta definição. Esse incêndio suscitou um amplo debate a respeito das condições apropriadas para a conservação de acervos de arte

16. Paulo Herkenhoff (1983).

17. Cesar Oiticica escreveu, em 1982, um pequeno texto sobre seu pai. Conferir Funarte (1983).

18. Paulo Herkenhoff (1983).

19. Sobre a participação de José Oiticica Filho no Photo Club Brasileiro, do qual foi diretor técnico em 1950, e do Foto Cine Clube Bandeirante, do qual foi "consócio", ver Maria Teresa Bandeira de Mello (1998) e Helouise Costa e Renato Rodrigues da Silva (2004).

20. Cf. o texto de Hélio Oiticica. em Funarte (1983, p. 7).

21. Sobre a recepção da arte abstrata no contexto brasileiro, ver Maria de Fátima Morethy Couto (2004).

22. Fernando Cocchiarale e Anna Bella Geiger (1987).

23. Idem, p. 11.

24. É importante observar que na Semana de 22 não houve espaço para a fotografia ou o cinema. Os "novos" meios mecânicos não foram incluídos como arte moderna. Sobre isso, ver Ricardo Mendes (2003). a uma maior geometrização, perceptível na fotografia Composição óbvia, de $1954 / 1955$.

Interessante é o modo como Oiticica Filho sai dessa fase lainda que alguns críticos, como veremos, não pensem assim), e passa a dedicar-se à fotografia abstrata e, posteriormente, à concreta. Vale a pena conferir o que Hélio Oiticica escreveu, por volta de 1967, sobre a trajetória artística de seu pai:

Sua evolução fotográfica é variada e complexa, levando-o, nos últimos anos, a descobertas bem individuais com suas Derivações e Recriações, e sua mestria no preto e branco, na "definição" e no "contraste" restam insuperáveis. [...] Com o tempo, tendo como que transformado a fotografia num verdadeiro campo experimental, e após o contato com a arte moderna (Bienais paulistas, grupos de vanguarda, para os quais colaborou com Fotografias concretas em 1957, e com as já citadas Derivações e Recriações posteriormente), passa a pintar, primeiro como acessório aos fotogramas que executava na época, e depois como pintura mesmo (sempre abstrata, geométrica ou não) ${ }^{20}$.

Assim, sua trajetória de fotógrafo original, engajado na expansão do campo fotográfico, é colocada por seu filho, expoente da arte vanguardista brasileira, como tendo profundas relações com a arte moderna. E esta relação com as artes visuais do período é bastante importante para ser abordada no caso de ambos os fotógrafos em estudo, visto que suas imagens experimentais dialogam com as pinturas e esculturas da época.

Contexto brasileiro das artes visuais de 1940 até o início da década de 1960 é marcado pela consolidação de instituições de arte e pela forte presença de debates em relação à arte abstrata ${ }^{21}$. Esses debates, em conjunto com os novos museus de arte, foram um campo fértil para o surgimento de dois movimentos artísticos bastante importantes: o Concretismo e o Neoconcretismo. As fotografias de Geraldo de Barros e de Oiticica Filho são marcadas por esses novos ares.

No final da década de 1940, com intervalo de apenas um ano, surgem em São Paulo dois museus de arte, decorrentes da iniciativa privada de grandes empresários. Em 1947, Assis Chateaubriand, diretor dos Diários Associados e fundador da TV Tupi, criou o Museu de Arte de São Paulo, o Masp. No ano seguinte, Francisco Matarazzo, dirigente de um grande complexo industrial, criou - Museu de Arte Moderna de São Paulo, o MAM. Estas instituições foram muito importantes para a divulgação da arte moderna no Brasil, especialmente a arte abstrata.

Conforme Fernando Cocchiarale e Anna Bella Geiger ${ }^{22}$, o surgimento dos primeiros núcleos de artistas abstratos no Rio e em São Paulo ocorre entre 1948 e 1949, criando uma oposição entre os artistas brasileiros. Artistas como Di Cavalcanti e Portinari mostram-se contrários a essa vertente não-figurativa, pois seria uma arte que se afasta da realidade, "a abolição da 'figura' isola a obra do artista de uma visualidade reconhecível, e, o que é mais grave, da realidade social de seu povo"23. A arte abstrata se afastaria dos ideais de nacionalidade que permearam os trabalhos dos artistas da Semana de $22^{24}$. Para a formação dos artistas brasileiros no campo da abstração, a Bienal de São Paulo foi de suma 
importância. Marcadas pela presença de importantes artistas abstratos, como Max Bill (que introduz idéias concretistas no país na I Bienal)25,

as primeiras edições da Bienal foram profundamente cortadas por polêmicas calorosas le por vezes maniqueístas), sobretudo entre os críticos que atacavam os "formalismos modernos", responsabilizando-os por esvaziar o valor social e militante da arte, contra os defensores das "novas formas" de intervenção e corte [...] do abstracionismo, tanto geométrico quanto o formal-que, aliás, também estavam em confronto uns com os outros ${ }^{26}$.

Assim, é possível ver que estava em jogo um debate não apenas entre figuração e abstração, mas também entre os diferentes tipos de abstração. Tal debate ocorre também na fotografia, ainda que de forma marginal. Marcada pela homologia com o real, a fotografia sempre foi figurativa, sendo este, justamente, seu grande atrativo. Ao entrar na abstração, a partir do contato dos fotógrafos com esse ambiente artístico experimental e inovador, a fotografia altera seu estatuto, ingressando de modo mais direto no campo das artes plásticas.

Mário Pedrosa, importante crítico e defensor da arte abstrata, a respeito dos trabalhos fotográficos de Geraldo de Barros, escreveu que ele "foi o primeiro a fazer da fotografia dita de arte não esse enlanguescimento pictórico do gosto convencional, mas uma experiência viril de imagens instantâneas ou fixadas, simultâneas ou dissolvidas em signos da vida e do espaço urbanístico"27.

Com este excerto de Pedrosa, é possível perceber como os trabalhos fotográficos experimentais de Barros se inseriam no novo momento da arte brasileira, marcado pela presença da arte abstrata e pelo Movimento Concretista, do qual ele fazia parte. Ainda que suas fotografias tenham sido feitas antes do seu engajamento no Grupo Ruptura ${ }^{28}$, em 1952, é possível pensar que as questões norteadoras do concretismo - hierarquia de forma, cor e fundo, junto com geometrizações das figuras - podem ser vistas em suas imagens. Entretanto, assim como nas fotografias de José Oiticica Filho, algumas delas são abstrações informais, demonstrando o alto grau de proficuidade de seu trabalho.

É interessante também pensar no papel que o Foto Cine Clube Bandeirante $29^{29}$ (FCCB), principal propagador da estética moderna na fotografia, tem em relação a Geraldo de Barros e José Oiticica Filho, e em como esta instituição se relacionou com o ambiente artístico da época. Com esta análise, pretendo mostrar de que modo as fotografias experimentais desses fotógrafos estavam em consonância com o momento das artes visuais no Brasil, voltado para a abstração, através do concretismo. Entretanto, a tentativa de alinhar fotografia e artes visuais é um tanto delicada, visto que, desde o surgimento da fotografia, ela é vista como uma arte mecânica, entendida como menos importante do que as artes ditas liberais, compostas pelas tradicionais pintura e escultura.

Helouise Costa ${ }^{30}$, em texto sobre a legitimação da fotografia pelo sistema de arte no Brasil, apresenta algumas reflexões interessantes sobre a relação entre o Foto Cine Clube Bandeirante, os museus de arte paulistas, e a Bienal de São Paulo. Assim, a autora busca, em um primeiro momento, entender como a
25. Na I Bienal, em 1951, Max Bill e Ivan Serpa ganharam prêmios com trabalhos em abstração.

26. Francisco Alambert e Polyana Canhête (2004, p. 45).

27. Mario Pedrosa (2000, p. 258).

28. O Grupo Ruptura era formado por Lothar Charoux, Waldemar Cordeiro (seu principal teórico), Geraldo de Barros, Kazmer Fejer, Leopoldo Haar, Luis Sacilotto e Anatol Wladyslaw. Eles propõem uma ruptura com questões plástico-formais, com todo um passado que as vanguardas européias haviam cortado desde o Impressionismo. Cf. João Bandeira (2002).

29. Sobre a importância do Foto Cine Clube Bandeirante na formação de uma fotografia moderna no Brasil, ver Helouise Costa e Renato Rodrigues da Silva (2004).

30. Helouise Costa (2008). 
31. Idem, p. 134-135.

32. Segundo Costa (idem, $\mathrm{p}$ 136), Geraldo de Barros descreveu todo o processo que levou o Clube a ocupar esta sala. Ver Barros (1954).

33. Conferir Helouise Costa e Renato Rodrigues da Silva (2004, p.43).

34. Geraldo de Barros já trabalhava com pintura antes de iniciar seu trabalho com fotografia. Posteriormente, torna-se um dos signatários do Manifesto Ruptura (1952). fotografia entrou no Museu de Arte Moderna de São Paulo, principalmente a partir de parcerias com o Foto Cine Clube Bandeirante:

A missão institucional de difusão e consolidação da arte moderna justificou a preocupação em inserir a fotografia como uma das modalidades artísticas contempladas pelo Museu de Arte Moderna de São Paulo logo após a sua fundação. Essa preocupação materializou-se não só na presença dos fotógrafos Thomaz Farkas, Francisco Albuquerque, Benedito Duarte e Eduardo Salvatore em comissões formadas no Museu, como também na inclusão imediata da fotografia na programação de exposições. Foram ao todo nove mostras de fotografia realizadas entre 1949 e 1985. [...] As primeiras cinco exposições comprovam o papel preponderante exercido pelo Foto Cine Clube Bandeirante (FCCB) junto ao MAM-SP até meados dos anos $1950^{31}$.

Com isto, podemos perceber que, em um primeiro momento, o Foto Cine Clube Bandeirante teve uma participação importante dentro do circuito das artes no Brasil. Sua participação consistia em montar exposições de fotógrafos do próprio fotoclube (como foi o caso da Sala Especial na II Bienal, em 195432) e também na intermediação de exposições internacionais, como a de Otto Steinert, ocorrida em 1955. Entretanto, apesar de ter exercido papel preponderante durante a década de 1950 (por ser o único segmento organizado entre os praticantes da fotografia) e também ter tido sua produção reconhecida pelos organizadores da Bienal, o FCCB perdeu este espaço no início da década de 1960 e com o regime militar.Outros aspectos importantes a serem mencionados na tentativa de ligar Geraldo de Barros e José Oiticica Filho aos espaços institucionais de arte, além da participação dos fotoclubistas na Bienal de São Paulo, é o fato de Geraldo de Barros ter sido chamado a montar, em 1949, o Laboratório de Fotografia do Masp, junto com Thomaz Farkas e German Lorca ${ }^{33}$, e ter ligações com as artes plásticas desde antes de sua associação ao FCCB, também em 194934. Assim, ainda que a fotografia em si não tenha sido plenamente aceita pelos museus, visto que sua incorporação aos acervos institucionais não ocorre nesta época, parece-me importante atentar para a circulação que Geraldo de Barros teve entre os dois ambientes, tanto o artístico - visto que sua exposição Fotoformas ocorreu no Masp, em 1951 - como o fotoclubístico, promovendo um intercâmbio, ainda que inicial, entre essas duas instâncias. A importância de suas imagens está em fazer com que a fotografia seja vista também como arte, visto que os valores trabalhados por ela contribuíram para a expansão das possibilidades da câmera fotográfica. Segundo Mário Pedrosa:

Baseado nos fundamentos da estética do concretismo de Vantongerloo-Bill, logo se formou em São Paulo um grupo de artistas jovens e entusiastas em torno de Waldemar Cordeiro, cuja inquietação teórica fez dele um centro propulsor de idéias, por vezes incômodo ou estéril, mas frequentemente estimulante: um Geraldo de Barros, de formação já diferente, pois participou com Mavignier, Palatnik, dos nossos entusiasmos pelos artistas de Engenho de Dentro e foi o primeiro a fazer da fotografia dita de arte não esse enlanguescimento pictórico 
do gosto convencional, mas uma experiência viril de imagens instantâneas ou fixadas, simultâneas ou dissolvidas em signos da vida e do espaço urbanístico ${ }^{35}$.

Podemos perceber, a partir deste excerto, que Barros tinha a aceitação de um dos principais críticos de arte do Brasil, responsável, junto com Ferreira Gullar, por propagar a abstração em nosso país. Pedrosa classifica as fotografias de Barros como "dita de arte", ou seja, vê nelas, no mínimo, potencial artístico, diferente de uma fotografia tradicional, voltada ao documental ou ao pictorialismo. Tais fotografias estariam alinhadas aos fundamentos do concretismo ${ }^{36}$.

Do mesmo modo, José Oiticica Filho participava do ambiente artístico neoconcreto do Rio de Janeiro, juntamente com seus filhos. Pode-se dizer que o início da ruptura neoconcreta ${ }^{37}$ tenha sido marcada pela Exposição Nacional de Arte Concreta, que aconteceu em 1956, no Rio de Janeiro, e, no ano seguinte, em São Paulo. Foi então que começaram a mostrar-se latentes as divergências entre os concretistas paulistas e cariocas, culminando com o lançamento do Manifesto Neoconcreto, em 1959. Em linhas gerais, o neoconcretismo buscava fugir do racionalismo exagerado do Concretismo, bem como do dogmatismo geométrico e das ortodoxias construtivas, recuperando as possibilidades criadoras do artista. Assim, procurava, através de uma arte que usava cor e formas livres, recuperar o papel do artista, deixando de enfatizar o caráter industrial da obra de arte. Ronaldo Brito assinala algumas diferenças entre o concretismo e o neoconcretismo:

neoconcretismo, por sua vez, obedecia às prescrições do sistema acerca da atividade cultural: era praticamente apolítico, mantinha-se no terreno reservado, era tímido e desconfiado em relação à participação da arte na produção industrial. Comparados aos agentes da arte concreta, investidos muitas vezes de funções práticas enquanto publicitários e designers, os artistas neoconcretos eram quase amadores - por mais que projetassem transformações sociais a partir da arte, permaneciam necessariamente no terreno especulativo, no terreno da arte enquanto prática experimental autônoma. A inserção neoconcreta se dava num espaço menos abrangente e mais tradicional do que a arte concreta, levando-se em conta estritamente a participação do artista na produção social ${ }^{38}$.

Deste ponto de vista, podemos pensar que Geraldo de Barros - por sua atividade como designer, especialmente em sua atuação na Unilabor ${ }^{39}$, e em seus trabalhos posteriores ao estilo pop arte - diferencia-se substancialmente de José Oiticica Filho, cuja atuação sempre se deu no campo da fotografia, buscando seu aprimoramento e sua consagração como forma de arte.

Segundo Paulo Herkenhoff, a última fase de José Oiticica Filho, depois de ter passado pela utilitária, fotoclubista e abstrata, é a de fotógrafo construtivo ${ }^{40}$. Segundo o autor,

O contato de José Oiticica Filho com o movimento construtivo brasileiro nos anos 50 foi bastante intenso. Além da convivência pessoal estreita com os artistas mais atuantes da época, especialmente seu filho, Hélio Oiticica, há registros de suas visitas às Bienais de São Paulo e a exposições de artes plásticas. Nessas oportunidades fotografou obras de artistas construti-
35. Mario Pedrosa (2000, p. 251).

36. Sobre o concretismo e Waldemar Cordeiro, ver Helouise Costa (2002).

37. Ver Ronaldo Brito (1999).

38. Idem, p. 60-61.

39. Sobre a Unilabor, ver Mauro Claro (2004).

40. Paulo Herkenhoff (1983, p. 15). 
41. Idem, p. 16

42. Ibidem.

43. Ibidem.

44. Rubens Fernandes Júnior (2006, p. 11). vos estrangeiros e nacionais, como Sophie Tauber-Arp e Ivan Serpa. Uma curiosidade, que não deixa de ter um significado ponderável, é o fato de ter executado a marcenaria de muitos dos objetos e projetos de Hélio $^{41}$.

Esta convivência com o ambiente construtivo foi bastante profícua para a elaboração dos processos e intenções de trabalho de Oiticica Filho. Segundo ele, "a recriação fotográfica é, ao meu ver, um método interessantíssimo para estudos e pesquisas em artes visuais sob um ponto de vista geral, e não apenas fotográfico" 42 . $\bigcirc$ fotógrafo mostra-se interessado em descobrir novas formas plásticas em suas imagens. É possível, por exemplo, estabelecer um comparativo entre suas fotografias e os Metaesquemas de Hélio Oiticica, no que tange principalmente à composição. Segundo Herkenhoff, "em ambos há um módulo-padrão desdobrado de modos diversos (alterações nos ângulos, nas dimensões, na direção), distribuído no espaço com extremo dinamismo"43.

Assim, acredito que a presença da fotografia nos acervos dos principais museus é apenas uma das variáveis que deve ser levada em conta ao analisar-se o processo de legitimação da fotografia enquanto arte. Como foi possível perceber nesta pequena contextualização das fotografias de Geraldo de Barros e José Oiticica Filho, estes fotógrafos foram extremamente criativos ao trabalhar com a fotografia, explorando ao máximo seu potencial poético, buscando criar obras que refletissem o momento atual das artes visuais. Participaram, ao seu modo, deste ambiente, contribuindo amplamente para a aceitação da fotografia enquanto objeto artístico.

Para continuar o percurso historiográfico sobre as fotografias destes fotógrafos, é preciso mergulhar um pouco nos conceitos utilizados para descrevê-las. A seguir, procuro fazer um balanço bibliográfico a respeito dos fotógrafos.

Revisão conceitual

Neste ponto, é preciso fazer uma digressão para entender de que modo as fotografias de Geraldo de Barros e de José Oiticica Filho podem ser entendidas em termos conceituais, visto que os vários autores que pensaram a respeito de tais imagens (e não apenas as destes artistas) vão denominá-las de modos bastante diferentes. É preciso definir esses modos, a fim de melhor entender as implicações de cada um deles.

As fotografias de Geraldo de Barros e José Oiticica Filho podem ser inseridas na idéia de "campo expandido" da fotografia. Segundo Rubens Fernandes Júnior, criador da idéia,

A fotografia expandida existe graças ao arrojo dos artistas mais inquietos, que, desde as vanguardas históricas, deram início a esse percurso de superação dos paradigmas fortemente impostos pelos fabricantes de equipamentos e materiais, para, aos poucos, fazer surgir exuberante uma outra fotografia, que não só questionava os padrões impostos pelos sistemas de produção fotográficos, como também transgredia a gramática do fazer fotográfico ${ }^{44}$. 
Rubens Fernandes Júnior, influenciado por Flusser, apresenta uma idéia geral de transgressão do fazer fotográfico tal como foi concebido desde o surgimento do aparelho fotográfico, utilizado amplamente pelos fotógrafos documentais, como Atget, Bresson ou Salgado. Assim, as experimentações feitas por Geraldo de Barros e José Oiticica Filho estariam incluídas nessa concepção, visto que elas alargam o campo de atuação da fotografia, aproximando-o do campo artístico, por exemplo. Mas as práticas fotográficas constituintes deste "campo expandido", principalmente na contemporaneidade, são muitas, o que torna, esse, um termo de aplicação operacional genérica.

Em catálogo publicado em 1936, pelo Museu de Arte Moderna de Nova lorque, Alfred Barr ${ }^{45}$, curador da exposição Cubism and abstract art ${ }^{46}$, cunha o termo "fotografia abstrata". Usando como exemplo apenas os artistas Man Ray (com suas rayografias), Moholy-Nagy e Bruguiere, Barr descreve em poucas linhas o que ele acredita ser a fotografia abstrata. Assim, no texto do catálogo, Barr explica:

Man Ray foi também um pioneiro na fotografia abstrata. Ele foi provavelmente o primeiro a fazer uso da técnica rayográfica para fazer composições abstratas. Ao fazer uma rayografia, nenhuma câmera é usada; objetos são colocados diretamente sobre o papel sensível, que então é revelado. Com objetos como um matador de moscas, um ovo de cerzir, anéis de metal e um cacho de cabelo, Man Ray obteve composições de grande sutileza (fig. 186, 187). Elas foram aclamadas pelos companheiros dadaístas de Man Ray pela sua técnica anti-" artística" e aparentemente casual, mas muitas delas são, de fato, trabalhos de arte completos diretamente relacionados com a pintura abstrata e não ultrapassados no seu medium. O húngaro Moholy-Nagy, antigo professor da Bauhaus de Dessau, foi, até sua recente mudança para Londres, um dos mais inventivos e originais mestres do fotograma (fig. 188), outro nome do rayograma.

Francis Bruguiere, um americano morando em Londres, usa a câmera na feitura de fotografias abstratas de luz caindo em papel branco dobrado ou amassado ${ }^{47}$.

Nota-se que, nessas poucas linhas, o autor tenta organizar o conhecimento a respeito dessas fotografias que fogem aos padrões normais do que uma fotografia seria: cópia do real, mimética por natureza. Utiliza-se de termo usado nas artes e que, no momento, está recém se consolidando, e o aplica para o caso da fotografia feita por artistas. Fica a pergunta de porque Barr deixa de fora alguns fotógrafos, como Alvin Langdon Coburn, que, já em 1917, fazia experimentações no campo expandido da fotografia, criando as já citadas vortografias. Talvez se optasse por incluir Coburn, que atua apenas como fotógrafo, tivesse de rever a ligação estabelecida com a pintura abstrata, visto que esse fotógrafo não mantinha relação com os movimentos artísticos do período, apenas com o Vorticismo, que não figura no famoso quadro explicativo da arte moderna de Barr ${ }^{48}$.

Coburn, segundo Helmut Gernshein ${ }^{49}$, foi o primeiro a fazer fotografias abstratas. Ele acreditava que as possibilidades da câmera fotográfica ainda não haviam sido exploradas completamente e, por isso, iniciou uma série de experimentos que culminariam na série de 18 vortografias ${ }^{50}$, já mencionada. Também foi o responsável pela organização de uma exposição de fotografia abstrata, na qual
45. Alfred Barr (1974).

46. Sobre esta exposição, ver Susan Noyes Platt (1988).

47. Idem, p. 170; tradução da autora.

48. Apesar de o resultado plástico ter semelhanças com o Cubismo, ao que se sabe, Coburn não teve influências cubistas, mas sim do Vorticismo de Pound.

49. Helmut Gernsheim (1990).

50. Para fazer estas fotografias, Coburn criou uma câmera parecida com um caleidoscópio, utilizando três espelhos dispostos na forma de um triângulo, colocados acima da lente da câmera, refletindo, assim, uma imagem fragmentada. 
51. Paulo Herkenhoff (1983, p. 13).

52. Filiberto Menna (1977, p. 50-52); tradução da autora.

53. László Moholy-Nagy apud Filiberto Menna (1977, p. 50); tradução da autora. buscava a "apreciação do extraordinário". Entretanto, no caso de Gernsheim conhecido fotógrafo e historiador da fotografia -, o termo "fotografia abstrata" não tem um uso crítico, apenas operatório.

Na esteira dessa terminologia, Paulo Herkenhoff, em 1983, escreve para o catálogo da exposição de fotografias de José Oiticica Filho aquilo que entende por fotografia abstrata. Segundo o autor,

É preciso demarcar o significado do termo fotografia abstrata, com o qual se pretende operar este texto. Inicialmente, opõe-se ao figurativo: é a emergência de imagens fotográficas não-identificáveis com objetos naturais e artificiais, é um não-verismo. [...] imagens não-figurativas (informais ou geométricas), produzidas conforme os processos tradicionais (registro e cópia) e os cânones codificados para a arte fotográfica - sem exclusão de alguns de menor uso, como o fotograma, a solarização, a fotomontagem, já então consagrados na história da arte (introduzidos por Man Ray, Moholy-Nagy, Rodchenko, Grosz, Heartfield, Haussman, El Lissitzky, Ernst, Dali, e outros) ${ }^{51}$.

Assim, Herkenhoff acompanha Barr em sua terminologia e exemplo de artistas abstratos, ainda que sua explicação seja um pouco mais complexa. A fotografia abstrata é colocada em oposição à fotografia figurativa, reproduzindo uma dicotomia oriunda das artes plásticas. É também colocada em condição de suspeita, pois é definida como uma imagem fotográfica não-identificável com objetos naturais e artificiais. Deixa-se de lado outras possibilidades de abordagem, como o caráter narrativo ou descritivo da fotografia, que é inexistente em Barros e Oiticica. Nesse caso, talvez fosse interessante considerar termos como fotografia não-narrativa ou fotografia não-denotativa, como alternativas para a crise de conceituação de tais imagens.

Filiberto Menna, em obra de 1975, intitulada La opción analítica en el arte moderno ${ }^{52}$, dedica-se ao que chama de fotografia analítica, bem como elabora o termo antifotografia. Segundo esse autor, a prática analítica da arte assumiu a tarefa de desmascarar a pretensão da fotografia de figurar como equivalente da visão natural. Tal concepção revela a natureza convencional, histórico-cultural que permeou as idéias sobre a fotografia desde o seu início. Entretanto, Menna, em sua análise, desarticula esse postulado ao considerar especialmente os fotogramas dentro do que Moholy-Nagy afirmou sobre eles:

A concreção do fenômeno da luz é peculiar ao processo fotográfico e a nenhuma outra invenção técnica. A fotografia sem câmera (a construção de fotogramas) embasa-se nisso. $\bigcirc$ fotograma é uma realização de tensão espacial em branco-preto-cinza [...] Embora careça de conteúdo representativo, o fotograma é capaz de evocar uma experiência ótica imediata, baseada em nossa organização visual psicobiológica ${ }^{53}$.

Assim, o fotograma traduz o objeto em motivo luminoso não-figurativo, criando uma relação ótica elementar, parecida com a pintura construtivista. $\bigcirc$ autor não menciona o termo fotografia abstrata, mas elabora uma série de técnicas de détournement, tais como fotomontagem, solarização, negativo, uso de objetivas especiais e lentes deformadoras, que definiriam a elaboração de "antifotografias": 
"Em definitivo, trata-se de verdadeiras 'antifotografias', que pulverizam as expectativas do espectador, destroem a confiança nas qualidades reprodutivas do meio, em suma, provocam uma espécie de 'ginástica mental' que desloca a atenção do referente para o signo lingüístico" 54 .

Essas antifotografias colocam em discussão o que Menna chama de "iconismo fotográfico", que vem a ser a importância da representação figurativa na fotografia. As fotografias nas quais não há elementos denotativos, tais como os fotogramas, as múltiplas exposições, e todas as outras imagens produzidas sem que o referente seja identificado pelo espectador, podem ser enquadradas como antifotografias, pois criam um sentimento de suspeita, contribuindo para a complexidade da imagem.

Em 1977, Rosalind Krauss escreveu o texto Photography and abstraction ${ }^{55}$, no qual desenvolveu uma análise bastante filosófica, e semiótica, a respeito da possível existência de fotografias abstratas, contrapondo-se à concepção de Barr. A autora inicia o artigo analisando uma fotografia de um exercício sobre luz e superfície, realizado na Escola da Bauhaus, que consistia em dobrar uma folha de papel formando pregas ritmadas, para, ao receber uma forte luz rasante, tornar-se um jogo de puro desenho, formas visuais puras. Tal jogo abstrato de relações e inversões de figura e fundo, para nós, é uma fotografia. Krauss afirma que:

Esta fotografia não é a demonstração das condições abstratas da visão. Ela o é de algo, é a marca documental daquela coisa que foi registrada fotoquimicamente na película, a imagem de uma folha de papel recortada e dobrada. Não pode livrar-se dessa condição. Lissitzky, Moholy-Nagy, Man Ray, Brugière, Berenice Abbott, Imogen Cunningham [...] nenhum deles a defendeu, ainda que tenham experimentado com a "fotografia abstrata"

Assim, o conceito de fotografia abstrata começa a ser questionado, trazendo um problema para o desenvolvimento da pesquisa sobre Geraldo de Barros e José Oiticica Filho. Percebe-se que foi um termo operativo cunhado por críticos, e não, pelos próprios artistas e fotógrafos. Dentro da lógica de Krauss, as fotografias feitas por Geraldo de Barros a partir de cartões perfurados não seriam uma abstração. Sabemos que aqueles são cartões perfurados, mas o modo como o autor os fotografa abre uma dúvida, ou uma suspeita, a respeito de sua identificação. É por esse motivo que o termo, também de certo modo genérico, fotografia sem referente claramente identificável, parece, em alguns casos, mais apropriado.

Rosalind Krauss vai além em sua análise, e, ao chegar no punctum barthesiano, a autora afirma que "esta ferida infligida pela fotografia existe em função da maneira como a foto entrega o real de seus conteúdos, marcando-thes não apenas com o ser - "isto é" -, mas de forma irrevogável com o tempo: "isto foi" 57 . A autora coloca, assim, a questão da relação da fotografia com o passado e com o acontecimento. $\bigcirc$ que, segundo ela, ocorre no caso de fotografias supostamente abstratas - para isso ela utiliza fotografias de James Welling - é
54. Filiberto Menna (1977, p. 51); tradução da autora.

55. Rosalind Krauss (2004).

56. Idem, p. 231 ; tradução da autora.

57. Idem, p. 233. 
58. Idem, p. 235.

59. Ibidem.

60. Ibidem.

61. Arlindo Machado (1984, p. 155). uma queda na "incerteza" e no "silêncio". "Vemos o referente, mas não o reconhecemos. Perdemos o encontro" 58 .

O trabalho de Welling é baseado em um diário escrito por sua tataravó em 1840. As fotografias do diário criaram um marco para o que o artista buscava: "uma fotografia que não entregara o presente (fotografia de rua, do cotidiano, do instante decisivo), mas que, ao apresentar uma distorção temporal, colocou-o, a ele e aos espectadores, em contato com um passado que se encontrou demasiado tarde" 59 . Por isso a perda do encontro.

Torna-se tarde para reconhecer o objeto fotografado. Krauss, para explicar essa idéia, apropria-se do termo tuché, usado por Lacan e transformado por Barthes no punctum. A palavra indica "a realidade perdida, a realidade que já não pode produzir a si mesma a não ser repetindo-se incessantemente em um despertar jamais alcançado"60. Assim também o punctum faz com que o real seja tanto aquilo que eu perdi como o que estarei obrigado a reproduzir a partir de então por repetição. É por isso que Welling refotografa os lugares por onde sua tataravó passou, sobrepondo-os às páginas do diário escrito por ela, obtendo assim uma imagem obscura, não claramente identificável, "abstrata".

Por fim, em texto de 1984, intitulado A ilusão especular, Arlindo Machado mostra-se negativo em relação à própria possibilidade de existência de fotografia abstrata, devido, justamente, às suas características formativas. Segundo ele:

É curioso constatar que as fotografias ditas "artísticas" sejam, no geral, bem pouco severas em relação à ilusão especular e permaneçam, apesar de tudo, figurativas, por mais que tentem disfarçar essa condição com arranjos harmônicos e composições "musicais". [...] Daí o equívoco fundamental de José Oiticica Filho ao supor que poderia, numa certa fase de sua obra, construir uma fotografia "abstrata", debruçando-se sobre motivos informais, como traçados de tinta sobre vidro rugoso. $\bigcirc$ momento de abstração nas fotos de Oiticica é anterior à fotografia propriamente dita: por essa razão, tais fotos "abstratas" não são nem um pouco menos figurativas que qualquer pimentão hiper-realista de Edward Weston. É que, em quaisquer circunstâncias, a câmera e a película gelatinosa foram concebidas para possibilitar a emergência da figura, sem deixar brechas para qualquer outra exploração que não o ilusionismo de "real"6l.

Nota-se que o que parece ser fácil - encontrar um termo justo para referir-se a determinadas fotografias - mostra-se, em realidade, uma reflexão bastante profícua. Percebe-se que o termo "fotografia abstrata" não explica por si só as imagens fotográficas de Barros, Oiticica Filho e muitos outros. Ele apenas se refere ao fato de que o objeto da fotografia não se faz claro aos nossos olhos, mostra-se a nós de maneira "abstrata". Mas, se a fotografia é o registro de luz emanada por objetos reais em uma superfície fotossensível, é possível pensar em abstração, opondo-se, assim, à existência de uma figura? Não seria mais apropriado buscar outros modos de referir-se a determinadas imagens, sem engessá-las em uma terminologia demasiado genérica e, por vezes, inapropriada? Em alguns casos fotografia não-narrativa basta; em outros é preciso ir além, identificando-a como fotografia construtiva, de composição geométrica, com referente 
não-identificável, não-denotativa - o que melhor se aplicar à fotografia que se tem à frente.

Neste ponto, é importante retornar aos fotógrafos, encerrando este percurso de estudo com uma revisão bibliográfica dos principais textos escritos sobre eles.

Revisão Bibliográfica

Sobre Geraldo de Barros e José Oiticica Filho, pesquisadores e críticos de renome escreveram alguns textos que servem como baliza para uma primeira aproximação à pesquisa sobre tais personagens. Ao revisar tais textos, pretendo reafirmar a importância que tiveram na divulgação e na valorização do trabalho desses fotógrafos no contexto da fotografia nacional. Assim, trato de textos de Pietro Maria Bardi, Radhá Abramo, Annateresa Fabris, Maria Teresa Bandeira de Mello, Antonio Fatorelli, Helouise Costa, Paulo Herkenhoff, Heloísa Espada Lima e Paulo Henrique Camargo Batista. Entre artigos, ensaios, capítulos de livros e dissertações de mestrado, pretendo mostrar como esses fotógrafos foram construídos enquanto objeto de estudos pelos mais diversos autores, preocupados em sistematizar o estudo a respeito das obras de Geraldo de Barros e José Oiticica Filho.

Procurando manter uma ordem cronológica na abordagem dos textos, para que fique visível a tentativa de reconstrução crítica da historiografia a respeito desses fotógrafos, parece-me conveniente iniciar o percurso com dois pequenos ensaios, escritos respectivamente por Pietro Maria Bardi, em 1950, para o catálogo da exposição de Geraldo de Barros, Fotoformas, e por Radhá Abramo, em 1977, para o catálogo da exposição Geraldo de Barros: 12 anos de pintura 1964 a 1976, realizada no MAM-SP, em 197762. Bardi inicia seu ensaio para o catálogo da exposição Fotoformas afirmando que Barros tinha a composição como um dever, transformando segmentos lineares em harmonias formais agradáveis. Para o autor, o fotógrafo utiliza a fotografia como meio de fugir dos verismos da pintura, pois, ainda que a fotografia seja um meio verista por excelência, ela também "se presta a transformar a sensação numa expressão sem 'artisticidade', pura derivação de sombras e por isso mais ligada à abstração"63. Bardi encerra a apresentação às fotografias de Geraldo de Barros anunciando a viagem de estudos do fotógrafo a Paris, de onde ele voltaria, certamente, muito enriquecido. Já o texto de Radhá Abramo busca apresentar o artista e sua criação, por ocasião de sua exposição de pinturas. A autora não aborda tanto as fotografias quanto suas pinturas, que são caracterizadas por ela como "ambíguas"64. Entretanto, ao traçar a biografia de Barros, Abramo acaba por pincelar sua pesquisa fotográfica, elencando seu papel na organização do Laboratório de Fotografia do Masp, em 1949, e sua participação em inúmeras exposições fotográficas, nas quais é, inclusive, fotógrafo premiado. A autora também enfatiza a relação entre o cartaz, a fotografia e o design, todos objetos resultantes da criação de Barros. Segundo ela, "a criação do cartaz, da foto e do design envolve o objetivo da seriação, distribuição e
62. Estes dois ensaios encontram-se no livro de Geraldo de Barros (2006, p 137-138).

63. Pietro Maria Bardi apud Geraldo de Barros (2006, p. 137).

64. Radhá Abramo apud Geraldo de Barros (2006, p. 138). 
65. Radhá Abramo apud Geraldo de Barros (2006, p. 141).

66. Paulo Herkenhoff (1983, p. 10).

67. Paulo Herkenhoff apud Geraldo de Barros (2006, p. 147). Este texto foi publicado originalmente no jornal Folha de São Paulo, em 23 de outubro de 1987.

68. Idem, p. 148

69. Idem, p. 149

70. Idem, p. 150 consumo em larga escala"65. Ou seja, as características do concretismo estão presentes nos trabalhos de Barros como uma constante unificadora.

Paulo Herkenhoff escreveu três textos importantes para o tema em estudo. $\bigcirc$ primeiro deles, de 1983, é sobre José Oiticica Filho, e os dois últimos, de 1987 e 1989, são sobre Geraldo de Barros. O texto A trajetória: da fotografia acadêmica ao projeto construtivo busca traçar um panorama da obra de José Oiticica Filho, enumerando as quatro fases pelas quais o fotógrafo teria passado: o utilitário, o fotoclubista, o abstrato e o construtivo. Segundo Herkenhoff, "A obra de José Oiticica Filho representa uma experiência radical de ruptura na história da fotografia brasileira. $\bigcirc$ seu percurso, desde a participação no movimento fotoclubístico até o engajamento com o projeto construtivo, testemunha um equilíbrio entre o rigor técnico e uma inquietação intelectual questionadora"b6.

Desse modo, Herkenhoff estabelece categorias e relações para as diferentes imagens produzidas por Oiticica Filho, buscando também precedentes, paralelos, contatos e, por fim, a atualidade do fotógrafo no momento da arte brasileira contemporânea. Esse é, com certeza, um dos mais importantes e completos textos produzidos sobre José Oiticica Filho até o momento. E já se passam mais de 20 anos.

No texto A imagem do processo, de 1987, Paulo Herkenhoff contextualiza Geraldo de Barros como fotógrafo que busca a ruptura com a ordem vigente. Segundo ele, "É como fotógrafo que Geraldo de Barros fará sua inserção radical no processo cultural brasileiro, no momento da criação dos museus no Rio de Janeiro e São Paulo, da Bienal e sobretudo das discussões sobre o abstracionismo e a formulação do processo construtivo" 67 .

autor continua sua análise abordando o que chama de "projeto atualizador do fotoclubismo", em que Barros propõe uma ruptura, visto que suas fotografias operam no campo da percepção visual como construção abstrata, bem ao contrário dos postulados pictorialistas vigentes até então no ambiente fotoclubista. Geraldo de Barros, assim como José Oiticica Filho, vive um impasse entre a busca do abstrato e a permanência da figuração, sendo que a "abstração", para ele, é uma oposição à fotografia realista ${ }^{68}$. Segundo Herkenhoff, a importância da obra de Barros está na construção do signo e na fundação de uma outra fotografia. Ele estabeleceu uma nova lógica do olhar, com a ruptura das antigas certezas abalizadas pela fotografia ${ }^{69}$. $\bigcirc$ autor encerra $\mathrm{O}$ artigo afirmando que Geraldo de Barros, assim como José Oiticica Filho - a quem ele nunca conheceu - são desarticuladores da fotografia, corrompendo os cânones fotoclubistas, que, até então, eram as únicas alternativas para uma fotografia artística. Além de desarticulador de processos, imagens e mecanismos lógicos da fotografia, Barros também desarticula o tempo da imagem, ao não associá-la a um momento decisivo, mas a um processo construtivo ${ }^{70}$.

No texto Geraldo de Barros: a renovação e a constância, de 1989, Herkenhoff segue afirmando a importância do fotógrafo enquanto agente da dessacralização da fotografia no Brasil da década de 1950. Destaque neste artigo, e diferencial em relação ao anterior, é a ênfase do autor no processo de desenvolvimentismo que se instaura no Brasil nessa época. Depois de contextualizar 
amplamente o ambiente favorável à cultura nos anos 1950, passando desde o próprio desenvolvimentismo até a poesia e a crítica de arte, Herkenhoff coloca Barros dentro do movimento concretista paulista, do qual o fotógrafo faz parte com suas pinturas e como um dos signatários do Manifesto Ruptura. Assim, o autor afirma que: "As linguagens construtivas na América Latina, florescentes desde a década de 1940 até os anos 1960, na Argentina, Uruguai, Brasil, Colômbia e Venezuela, estão em relação com os planos de uma cultura organizada nos sonhos de modernização e desenvolvimento"7l.

Na mesma linha, o autor encerra o artigo afirmando que, nos anos 1950, a arte concreta podia ser relacionada com a utopia do desenvolvimento nacional. Do mesmo modo, as fotografias de Geraldo de Barros podem ser entendidas como pertencentes a esse ideal, em razão do rigor compositivo. Todos os textos de Paulo Herkenhoff têm como mérito o fato de terem realizado um apanhado crítico da obra desses fotógrafos, alçando-os a um outro patamar de reconhecimento pelo público e pelos estudiosos acadêmicos. Merece destaque também o livro A fotografia moderna no Brasil, publicado em 1995, com reedição em 2004, escrito por Helouise Costa e Renato Rodrigues da Silva. Esse livro, pioneiro, tem a importância de trazer à tona a formação de uma fotografia moderna brasileira, gestada no Foto Cine Clube Bandeirante (FCCB), em São Paulo. No que tange a Geraldo de Barros e José Oiticica Filho, os autores os colocam como a expressão máxima da fotografia moderna no Brasil. Geraldo de Barros ganha destaque por ser o primeiro fotógrafo moderno, membro do FCCB, a intervir no processo clássico de produção da fotografia - fotografar, revelar, ampliar -, "dando corpo a um profundo questionamento dos limites da linguagem fotográfica"72. Essa liberdade a que Barros se permitia ao criar suas imagens manteve-o ao largo das atividades do fotoclube, que, na época, não se encontrava aberto aos seus experimentos fotográficos. Entretanto, o fotógrafo, como já mencionado anteriormente, teve profunda influência nas relações entre o FCCB e a Bienal de São Paulo.

Os autores destacam José Oiticica Filho como tendo grande importância no ambiente fotoclubista carioca, sendo um dos principais divulgadores da sensibilidade moderna. E acrescentam:

No entanto, enquanto o bandeirante lançava-se à experiência renovadora com a atuação dos pioneiros, José Oiticica Filho continuava preso ao academismo, sendo um defensor ardoroso dessa estética ${ }^{73}$. Somente a partir da segunda metade da década de 1950 ele implementou mudanças em sua produção, o que determinou o seu afastamento do fotoclubismo carioca e uma maior aproximação do Foto Cine Clube Bandeirante, onde seu trabalho de características modernas pôde ser divulgado ${ }^{74}$.

No FCCB, Oiticica Filho é visto como "um dos mais destacados mestres do abstracionismo fotográfico com suas derivações e recriações"75. Com essa análise, Helouise Costa e Renato Rodrigues Silva reafirmam a importância do trabalho do fotógrafo e mostram como ele passou pelas diversas fases da fotografia, como apresentado por Herkenhoff. Na edição de 1995 do livro, os autores
71. Paulo Herkenhoff apud Geraldo de Barros (2006, p. 157). Este texto foi publicado originalmente em 1989, para o catálogo da exposição no Museu de Arte Moderna do Rio de Janeiro.

72. Helouise Costa e Renato Rodrigues da Silva (2004, p 43).

73. Neste sentido, José Oiticica Filho tem uma série de artigos publicados a respeito das principais técnicas pictorialistas de fotografar.

74. Helouise Costa e Renato Rodrigues da Silva (2004, p. 72).

75. Idem, p. 73 
76. Idem, p. 75. Ver também Helouise Costa e Renato Rodrigues da Silva (1995).

77. Annateresa Fabris (1998).

78. Maria Teresa Bandeira de Mello (1998).

79. Annateresa Fabris (1998, p. 69).

80. Idem, p. 71.

81. Idem, p. 74.

82. Cf. José Oiticica Filho (1958).

83. Maria Teresa Bandeira de Mello (1998, p. 120). encerram a parte dedicada à Oiticica Filho situando-o não como pioneiro da fotografia moderna, mas como pertencente à fase de diluição dessa experiência. Já na edição de 2004, há uma reformulação desta posição, como é possível perceber no seguinte excerto:

Por fim, é importante ressaltar que, no contexto da fotografia brasileira, a produção de caráter abstracionista de José Oiticica Filho constitui um segundo momento, cabendo situá-lo como precursor em relação ao ambiente carioca. De fato, ele foi um fotógrafo que atuou de modo mais sistemático na ampliação das possibilidades dessa estética. Assim, o trabalho do artista deve ser localizado a partir de sua aguçada sensibilidade plástica, materializada em uma pesquisa de grande potencial reformulador no universo mais amplo das artes plásticas no Brasi ${ }^{76}$.

Com isso podemos perceber que houve, por parte dos autores, uma percepção de que José Oiticica Filho extrapola o ambiente fotoclubista, sendo considerado um artista que explora seu potencial poético através da fotografia, em consonância com o panorama das artes visuais brasileiras.

O texto de Annateresa Fabris, A fotografia além da fotografia: José Oiticica Filho (1947-1995)77, dialoga, em termos de idéias, com o que Maria Teresa Bandeira de Mello ${ }^{78}$ escreve a respeito de suas fotografias em texto do mesmo ano. Ambas enfatizam o caráter pictorialista da obra de Oiticica Filho, que teria sido mantido mesmo nas fases posteriores do fotógrafo. Para Fabris, "José Oiticica Filho afirma-se aos olhos do público como mais um adepto do fotopictorialismo"79. Ainda segundo a autora, mesmo suas fotografias da fase utilitária não podem ser dissociadas de seu interesse pelo pictorialismo. Para Fabris, "Se, de fato, luz e superfície são questões fundamentais para o Oiticica pós-pictorialista, o que não se pode deixar de levar em conta - e é isso o que o distancia da atitude dos fotógrafos evocados por Herkenhoff - é que sua visão de fotografia continua a ser informada pelos postulados da estética que ia abandonando" 80

Os fotógrafos evocados por Herkenhoff são Moholy-Nagy e Rodchenko, que pretendiam, através da fotografia, atingir uma "nova visão". A autora, neste caso, afirma que os princípios norteadores de José Oiticica Filho ainda são os do pictorialismo. Segundo ela, "Oiticica supervaloriza o papel da técnica, detectando o nascimento da fotografia no trabalho de laboratório, 'quanto se graduam os cinzas, as luzes, o corte'" 81 . Fabris refere-se à célebre entrevista concedida pelo fotógrafo a Ferreira Gullar, em 1958, na qual ele afirma a importância do trabalho em laboratório na criação das fotografias ${ }^{82}$. Maria Teresa Bandeira de Mello, na mesma linha de Annateresa Fabris, afirma a respeito das obras de Oiticica Filho: "É curioso observar que, mesmo depois de se libertar dos cânones fotoclubistas e de se entregar a experimentações modernizadoras, ainda podem ser encontradas em suas obras semelhanças com a concepção de fotografia pictorialista"83.

A seguir, Fabris analisa duas fotografias que, para ela, são o marco da transição, de Oiticica, do pictorialismo para a abstração: Triângulos semelhantes e Um que passa, ambas de 1953. Segundo ela, 
Em duas composições de 1953, Triângulos semelhantes e Um que passa, as preocupações geometrizantes do fotógrafo emergem de imediato, enfatizadas pelo contraponto definido pela presença da figura humana. A luz adquire uma conotação construtora ao contrário do efeito dramático que desempenhava no momento pictorialista. [...] $\bigcirc$ mesmo contraste entre abstração e presença do referente preside também Composição óbvia (1954-55), na qual Oiticica aprofunda mais a procura do campo bidimensional e a definição da fotografia em termos requintadamente tonais ${ }^{84}$.

Logo a seguir, apoiando-se em excertos da entrevista de Oiticica Filho de 1958, a autora conclui que o afastamento cada vez maior do referente é uma estratégia do fotógrafo para produzir obras de arte, visto que ele acreditava mais no resultado que se consegue obter no laboratório do que na produção da fotografia em si. Seguindo seu percurso de análise, a autora chega às Derivações e Recriações, as quais "exibem, por vezes, parentesco com a abstração informal dos anos 50"85. Analisando a série seguinte de suas obras, as Formas, Fabris afirma que "ao mesmo tempo em que está engajado na exploração da abstração informal, na estruturação de campos matéricos, de relações sutilmente tensionadas, Oiticica busca também uma linguagem de caráter construtivo que se resolve, de início, na série Formas" 86

Annateresa Fabris, por fim, enfatiza que José Oiticica Filho estava preocupado em pesquisar as "possibilidades da fotografia para além da fotografia", com isso querendo dizer que todas as manipulações por ele feitas nas imagens tinham como objetivo colocar tais imagens mais próximas da arte do que da própria fotografia, negando o específico fotográfico. $\bigcirc$ cerne da análise da autora pode ser resumido na seguinte citação:

O que se detecta no Oiticica construtivo é, no fundo, um paradoxo. A constituição de formas novas, a saída do código acadêmico que regia a experiência fotoclubista brasileira estruturam-se através da reedição da ideologia que guiava o fotopictorialismo, disposto a parecer tudo menos fotografia.

Ao dizermos isso, não queremos negar a contribuição de Oiticica à constituição de uma linguagem plástica renovada. Se ela é fundamental, é impossível, no entanto, não perceber que Oiticica foge, as mais das vezes, da questão do específico fotográfico para postular uma fotografia que negue a fotografia, sem parecer dar-se conta de que mesmo o recurso ao simulacro não o livrava do enfrentamento com o instante. Por mais que seus modelos fossem previamente elaborados, por mais que a imagem final fosse o produto dos tempos longos do laboratório, por mais que o negativo possuísse potencialidades próprias, existia a intermediação do aparelho e, portanto, o momento do disparo no qual o objeto se apresenta em sua conotação estrutural. Ao tentar negar isso, Oiticica reatualiza a ideologia do fotopictorialismo, não importa se em sentido abstrato ou concreto ${ }^{87}$.

É, portanto, de suma importância a análise exaustiva realizada por Fabris, no intuito de situar a obra de José Oiticica Filho dentro dos parâmetros tanto da história da fotografia quanto da história da arte. Análise atenta, crítica, que vem a complementar os textos de Paulo Herkenhoff e Arlindo Machado, por vezes discordando deles.
84. Annateresa Fabris (1998, p. 75).

85. Idem, p. 76 .

86. Ibidem.

87. Idem, p. 77-78. 
88. Ver Antonio Fatorelli (2000), onde o autor expande suas idéias sobre as diversas fases da história da fotografia, culminando com uma expansão do campo fotográfico, um apagamento das fronteiras entre fotografia $\mathrm{e}$ artes visuais, através da idéia de suspeita na fotografia, presentes neste artigo sobre José Oiticica Filho, em seu livro intitulado Fotografia e Viagem. Ver também Antonio Fatorelli (2003).

89. Antonio Fatorelli (2000, p. 141).

90. Heloísa Espada Lima (2006).

91. Paulo Henrique Camargo Batista (2006).
Antonio Fatorelli, no texto José Oiticica Filho e o avatar da fotografia brasileira ${ }^{88}$, é mais positivo em relação ao trânsito de estilos do fotógrafo. Para ele, esse movimento é decorrente de um espírito investigativo, que buscava diferentes soluções plásticas para determinados problemas. A análise de Fatorelli busca inserir a obra fotográfica de Oiticica Filho dentro do panorama maior da história da fotografia, e do embate que esta trava entre o estatuto de realidade e a prática de experimentações. Para o autor,

De modo condensado, e sem dispensar o brilho que acompanha as poéticas modernas, Oiticica refez, ao longo de sua trajetória de fotógrafo, o percurso realizado pelos principais movimentos fotográficos precedentes, apresentando e posteriormente superando, sucessivamente, os princípios da fotografia científica, da prática pictorialista e da estética purista moderna. Além de atualizar estes movimentos, a contribuição de Oiticica - particularmente de suas imagens da década de 50, identificadas com as propostas estéticas do movimento concretista - estende-se projetivamente às décadas de 60, 70 e 80, prenunciando o trabatho de vários artistas plásticos e fotógrafos, como Hélio Oiticica e Lygia Clark ${ }^{89}$.

Com isto, podemos perceber que Fatorelli busca contextualizar as pesquisas de Oiticica Filho no campo fotográfico e também artístico, relacionando-o com os diversos ambientes pelos quais o fotógrafo passou - fotoclubes e artístico, especialmente - e com os quais promoveu intercâmbios criativos. $\bigcirc$ autor aponta, também, a importância que esse fotógrafo teve para a emergência da fotografia-matéria ou pós-fotografia, na década de 1980, movimento do qual participam fotógrafos como Rosângela Rennó e Antonio Sagesse.

Por fim, é importante situar a produção acadêmica a respeito de Geraldo de Barros. Há duas dissertações de mestrado, ambas de 2006, acerca do fotógrafo. Heloísa Espada Lima escreveu a dissertação intitulada Fotoformas: a máquina lúdica de Geraldo de Barros ${ }^{90}$, na qual busca traçar um amplo panorama sobre a produção das fotografias de mesmo título. A autora relaciona as fotografias de Barros ao movimento construtivista e às vanguardas históricas ligadas à fotografia, bem como investiga a participação do fotógrafo em diversos grupos e ambientes artísticos, procurando com isso perceber possíveis influências. A autora fez um levantamento dos livros de fotografia disponíveis nas principais bibliotecas de São Paulo, a fim de estabelecer o quanto da história da fotografia recente era conhecida por Barros quando ele decidiu fazer sua série de Fotoformas. Também em seu trabalho há um estudo acerca da relação de Geraldo de Barros com o crítico Mário Pedrosa, e um mapeamento do contexto cultural paulistano, no qual suas fotografias foram gestadas. Sua dissertação constitui leitura obrigatória para todos aqueles interessados em estudar o trabalho de Geraldo de Barros.

Da mesma forma, a dissertação de Paulo Henrique Camargo Batista, intitulada Fotoformas: a poética do processo interventor de Geraldo de Barros na práxis fotográfica91, busca apresentar o trabalho de Barros a partir do ponto de vista tecnológico, buscando entender o rompimento que o fotógrafo produz ao intervir no processo de constituição da fotografia. $\bigcirc$ autor parte da idéia de 
intervenção no processo fotográfico e do rompimento com a programação da câmera, tendo como referencial teórico Vilém Flusser e Arlindo Machado. O ponto de vista de Batista é o de que Geraldo de Barros é um exemplo do rompimento conceitual e estético com o programa operatório da câmera fotográfica. Em artigo de 2007, Batista retoma sua abordagem a respeito das fotografias de Barros, propondo-se a refletir

sobre as possibilidades conceituais da fotografia como símbolo ou transformação do real, a partir da necessidade de se reconsiderar suas alternativas de classificação nesse campo teórico [...] Através dos trabalhos de Geraldo de Barros, exemplificaremos como uma imagem técnica, produzida a partir de um aparato fotográfico analógico, também pode ser considerada uma interpretação científica e, no caso das Fotoformas, passível de um resultado plasticamente criativo através de seu referente, afirmando, assim, sua natureza possivelmente simbólica ${ }^{92}$.

Com um ponto de vista diferente do de Heloísa Espada Lima, este também é um trabalho enriquecedor para os estudos sobre Geraldo de Barros. Enquanto Lima busca uma análise do campo das artes visuais, inserindo as Fotoformas nesse contexto, Batista utiliza-se do conjunto de imagens para explorar a questão da imagem técnica e suas diferentes possibilidades conceituais.

À guisa de conclusão, mas deixando espaços de discussão em aberto

Após este percurso fragmentado, é possível perceber toda a profundidade do estudo envolvendo as fotografias de Geraldo de Barros e de José Oiticica Filho. Quer sejam fotografias abstratas, não-narrativas ou simplesmente experimentais, certo é que estes fotógrafos contribuíram para o alargamento do campo fotográfico, bem como proporcionaram as possibilidades de existência de um amplo debate sobre o estatuto da fotografia. Ao dialogarem com as artes visuais, especialmente as relacionadas a experiências de vanguarda, como o concretismo, estes fotógrafos provam ter uma mente criativa, pronta a explorar diferentes poéticas visuais, em busca de novas sensações. Mas, além disso, são fotógrafos que inspiram novos fotógrafos e novos artistas a buscar sempre mais, a não se contentar com o que se apresenta como pressuposto, e a investigar e criar sempre novas possibilidades para o olhar do espectador. Ao historiador, tais fotógrafos proporcionam um desafio, pois situam-se dentro de um ambiente múltiplo, não se contentando em participar de apenas um setor. Isso leva o pesquisador a investigar um panorama bastante amplo, buscando condensá-lo na figura destes fotógrafos, que, em sua obra, incorporam a visualidade de sua época. 


\section{REFERÊNCIAS}

ADES, Dawn. Fotomontaje. Barcelona: Gustavo Gili, 2002.

ALAMBERT, Francisco, CANHÊTE, Polyana. Bienais de São Paulo: da era dos museus à era dos curadores. São Paulo: Boitempo, 2004.

BANDEIRA, João (org). Arte concreta paulista: documentos. São Paulo: Cosac \& Naify; Centro Universitário Maria Antonia da USP, 2002.

BARR JUNIOR, Alfred H., Cubism and abstract art. New York: The Museum of Modern Art, 1974.

BARROS, Geraldo. Fotoformas: Geraldo de Barros. São Paulo: Cosac Naify, 2006.

A sala de Fotografia. Boletim Foto Cine, ano 8, n. 87, mar. 1954.

BATISTA, Paulo Henrique Camargo. Fotoformas: a poética do processo interventor de Geraldo de Barros na práxis fotográfica. 2006. 182 f. Dissertação (Mestrado em Tecnologia) - Programa de Pós-Graduação em Tecnologia, Universidade Tecnológica do Paraná, Curitiba, 2006.

; SILVEIRA, Luciana Martha. Geraldo de Barros e a fotografia como conceito. Conexão: Comunicação e Cultura, Caxias do Sul, v. 6, n. 12, p. 29-50, jul.-dez. 2007.

BRITO, Ronaldo. Neoconcretismo: vértice e ruptura do projeto construtivo brasileiro. São Paulo: Cosac \& Naify, 1999.

BUSSELLE, Michael. Tudo sobre fotografia. São Paulo: Círculo do Livro, 1977.

CASA ANDRADE MURICY (Curitiba, PR). Fotografia subjetiva: a contribuição alemã 1948-1963: folder. Curitiba, 2008.

CHIARELLI, Tadeu. A fotomontagem como introdução à arte moderna: visões modernistas sobre a fotografia e o surrealismo. Revista Ars, São Paulo, v. 1, n. 1, p. 67-81, 2003.

CLARO, Mauro. Unilabor: desenho industrial, arte moderna e autogestão operária. São Paulo: Editora Senac São Paulo, 2004.

COCCHIARALE, Fernando; GEIGER, Anna Bella. Abstracionismo geométrico e informal: a vanguarda brasileira nos anos cinquenta. Rio de Janeiro: Funarte; Instituto Nacional de Artes Plásticas, 1987.

COUTO, Maria de Fátima Morethy. Por uma vanguarda nacional. Campinas: Editora da Unicamp, 2004.

COSTA, Helouise; SILVA, Renato Rodrigues. A fotografia moderna no Brasil. Rio de Janeiro: Editora da UFRJ, 1995.

A fotografia moderna no Brasil. São Paulo: Cosac Naify, 2004.

Waldemar Cordeiro e a fotografia. São Paulo: Cosac Naify; Centro Universitário Maria Antonia da USP, 2002. 
FABRIS, Annateresa. A fotografia além da fotografia: José Oiticica Filho (1947-1995). Imagens, Campinas, n. 8, maio-ago. 1998.

FATORELLI, Antonio. Fotografia e viagem: entre a natureza e o artifício. Rio de Janeiro: Relume Dumará, 2003.

José Oiticica Filho e o avatar da fotografia brasileira. Lugar Comum, Rio de Janeiro, v. 11, p. 141-158, 2000.

FERNANDES JÚNIOR, Rubens. Processos de criação na fotografia: apontamentos para o entendimento dos vetores e das variáveis da produção fotográfica. Facom, São Paulo, n. 16, p. 10-19, 2006.

GERNSHEIM, Helmut. Creative photography: aesthetic trends 1839-1960. New York: Dover, 1990.

HERKENHOFF, Paulo. A trajetória: da fotografia acadêmica ao projeto construtivo. In: FUNARTE, Núcleo de Fotografia. José Oiticica Filbo: a ruptura da fotografia nos anos 50: catálogo. Rio de Janeiro, 1983.

A imagem do processo. In: BARROS, Geraldo. Fotoformas: Geraldo de Barros. São Paulo: Cosac Naify, 2006.

Geraldo de Barros: a renovação e a constância. In: BARROS, Geraldo. Fotoformas: Geraldo de Barros. São Paulo: Cosac Naify, 2006.

KRAUSS, Rosalind. Fotografia y abstracción. In: RIBALTA, Jorge (org). Efecto Real. Barcelona: Gustavo Gili, 2004.

LIMA, Heloísa Espada. Fotoformas: a máquina lúdica de Geraldo de Barros. 2006. 159 f. Dissertação (Mestrado em Artes) - Escola de Comunicação e Artes, Departamento de Artes Plásticas, Universidade de São Paulo, São Paulo, 2006.

MACHADO, Arlindo. A ilusão especular. São Paulo: Brasiliense, 1984.

MELLO, Maria Teresa Bandeira de. Arte e fotografia: o movimento pictorialista no Brasil. Rio de Janeiro: Funarte, 1998.

MENDES, Ricardo. Once upon a time: uma história da história da fotografia brasileira. Anais do Museu Paulista, São Paulo, vol. 6-7, n. 1, p. 183-205, 1998-1999.

MENNA, Filiberto. La opción analítica en el arte moderno. Barcelona: Gustavo Gili, 1977.

MOHOLY-NAGY, László. Peinture, photograpbie, film et autres écrits sur la photographie. Paris: Gallimard, 2007.

OITICICA FILHO, José. Oiticica: "Fotografia se faz no laboratório". Jornal do Brasil, Rio de Janeiro: 24 ago. 1958. Suplemento Dominical de Artes Plásticas.

PEDROSA, Mario. A Bienal de cá e pra lá. In: ARANTES, Otília (org). Modernidade cá e lá: textos escolhidos, Mário Pedrosa, 4. São Paulo: Edusp, 2000. 
PLATT, Susan Noyes. Modernism, Formalism, and Politics: The Cubism and Abstract Art Exhibition of 1936 at the Museum of Modern Art. Art Journal: Revising Cubism, New York, v. 47, n. 4, p. 284-295, Winter 1988

WEES, William C. Ezra Pound as a Vorticist. Wisconsin Studies in Contemporary Literature, Madison, v. 6, n. 1, p. 56-72, Winter-Spring, 1965.

Pound's Vorticism: some new evidence and further comments. Wisconsin Studies in Contemporary Literature, Madison, v. 7, n. 2, p. 211-216, Summer, 1966.

SITES

$<$ http://www.iconica.com.br/?tag=jose-oiticica-filho $>$

<http://www.itaucultural.org.br>

Artigo apresentado em 8/2009. Aprovado em 3/2010. 